\title{
Two-Period Inventory Control with Manufacturing and Remanufacturing under Return Compensation Policy
}

\author{
Xiaochen Sun, Mengmeng Wu, and Fei Hu \\ School of Science, Tianjin University, Tianjin 300072, China \\ Correspondence should be addressed to Xiaochen Sun; xcsun@tju.edu.cn
}

Received 18 December 2012; Accepted 1 February 2013

Academic Editor: Xiang Li

Copyright ( 2013 Xiaochen Sun et al. This is an open access article distributed under the Creative Commons Attribution License, which permits unrestricted use, distribution, and reproduction in any medium, provided the original work is properly cited.

\begin{abstract}
As an effective way of decreasing production cost, remanufacturing has attracted more and more attention from firms. However, it also brings many difficulties to firms, especial when firms remanufacture products which they produce. A primary problem for the case is how to acquire the used product sold by the firm itself. In this paper, we consider a return compensation policy for acquiring used product from customers. Under this policy, the return quantity of used product is a proportion of demand. We study an inventory replenishment and production planning problem for a two-period inventory system with dependent return and demand. We formulate the problem into a three-stage stochastic programming problem, where the firm needs to make decisions on the replenishment quantity of new raw material inventory in each period and the production quantities of manufacturing and remanufacturing ways. We give the optimal production policy of manufacturing and remanufacturing ways for the realized demand and prove the objective function for each stage to be concave in the inventory replenishment quantity. Moreover, we prove that the basic inventory policy is still optimal for each period and give the analytical conditions of the optimal inventory levels which are unrelated to acquisition price. Finally, we investigate numerical studies to analyze managerial insights.
\end{abstract}

\section{Introduction}

With the development of global market competition, manufacturers constantly launch new products to substitute old products rapidly, which bring more and more end-of-use products into our life. Under the pressures of environmental protection and profit incentive, firms pay more and more attention to closed-loop supply chain (CLSC) management. Besides for the traditional production and selling process, CLSC also includes the process of taking back used products from customers, recovering their added value, and making recovered products reenter into the production system. In a closed-loop supply chain system, the decision-maker needs to consider more factors and decisions, and there are more uncertainties, for example, the uncertainties of used product returns on quantity, quality, and time, so managing closedloop supply chain is more difficult than only managing forward supply chain or reverse supply chain, even though a large number of firms still join the ranks of operating closed-loop supply chain as profit or cost factor. However, the difficulty also cannot be ignored. Therefore, how should a firm operate closed-loop supply chain system to create more profits is important when the firm faces more factors and uncertainties in closed-loop supply chain system.

Remanufacturing is an important way of reusing used product, which can recover the function of used product but need not to change the original structure of the product. It is a low cost and high efficiency reusing way. However, remanufacturing also requests the firm to be more familiar with the production technology of the used product; otherwise, the firm will suffer a very high cost. Therefore, remanufacturing a product produced by the firm itself is more effective and profitable. The most primary problem when a firm remanufactures its products is how to acquire used product effectively. Pricing strategies have been adopted in many industries and are effective for controlling customer demand. Therefore, it may also be an effective method for controlling the return of used products. In this paper, we consider a policy of acquiring used product, where the firm pays a return compensation for the customers who return used products. It is obvious the customers will be stimulated to return their used products. 
Under the return compensation policy, the random return depends on the random demand and it is influenced by the acquisition price of used products, and we consider an inventory replenishment and production planning problem in a two-period setting, where the firm's marketable products can be replenished by manufacturing way using new raw materials and remanufacturing way using used products. The firm needs to determine the inventory replenishment quantity of new raw material in each period, and the production quantities of manufacturing way and remanufacturing way. We formulate the problem into three-stage stochastic dynamic programming model and give all optimal decisions.

Our problem belongs to production planning and inventory control. However, most researchers assume that the return process is independent of the demand process, such as Fleischmann [1], Fleischmann and Kuik [2], Kiesmüller [3], Inderfurth [4], DeCroix and Zipkin [5], DeCroix [6], and Zhou et al. [7, 8]. Fleischmann et al. [9], and Dekker et al. [10] provide comprehensive reviews of production planning and inventory control.

Few papers consider the case that the return process is dependent on the demand process, except for the following research. Kiesmuller and van der Laan [11] investigated an inventory model for a single reusable product, where the random return depends on the demand based on the assumption that the selling quantity is approximately equal to the demand. The results show that it is necessary to consider the dependence between the demand process and the return process. Dobos and Richter [12] investigated a production/recycling system where customer demand and return rates are deterministic and stationary. They consider the EOQ environment with recovery and define return rate as a fraction of the constant demand rate. Atamer et al. [13] study an optimal pricing and production decision problem in utilizing reusable containers. They assume the return is a proportion of the demand under a single selling season.

Our work is mostly related to Atamer et al. [13], but they only considered a single-period setting. We consider a two-period setting, and another main difference from their research is that we consider a stochastic inventory problem, where the firm needs to make decisions on the replenishment quantities in each period and production decisions on remanufacturing and manufacturing. Moreover, we prove the existence of optimal inventory policy in each period and give the optimal policy structure.

The rest of this paper is organized as follows. In Section 2, we give the problem description and formulation. In Section 3, we provide the optimal analysis of the model and give the optimal policies. Numerical examples are provided in Section 4. Finally, we conclude our paper in Section 5.

\section{Problem Description and Formulation}

For a firm with manufacturing and remanufacturing production way, its marketable product inventory can be replenished by manufacturing way and remanufacturing way, and the products from different ways are homogeneous for the end customers, so we can assume that the selling prices

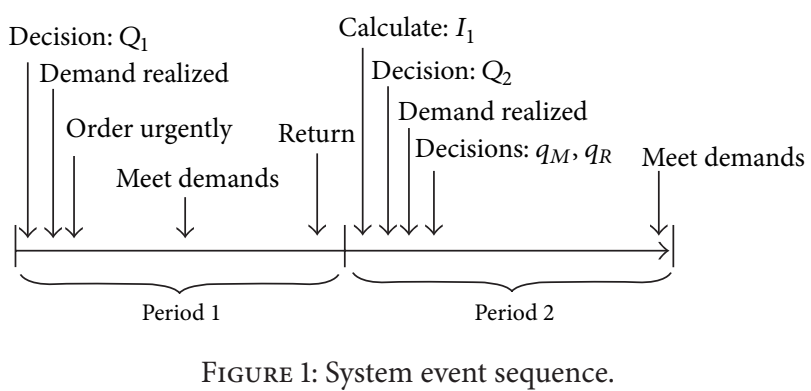

of products from different ways are the same. Generally, the production cost of remanufacturing way is less than manufacturing way, and the firm has a motivation to collect used product actively. For acquiring more used products more effectively, the firm offers a return compensation for the customers who return used products. We name the return compensation as acquisition price, denoted by $p_{R}$.

The demand in period $i$ for the marketable products is random, denoted by $D_{i}, i=1,2$. Under the return compensation policy, the return quantity of used products is related to the selling quantity. As only part of the customers return their used products, we assume it to be a proportion of selling quantity, and the proportion is affected by the acquisition price $p_{R}$ and is the increasing function in $p_{R}$, denoted by $\theta\left(p_{R}\right)$.

We consider a two-period production decision and inventory control problem in a production-to-order system. In each period, the firm needs to make decisions on the replenishment quantity of new raw material inventory before realizing the demand and determines the production quantities of manufacturing and remanufacturing way after realizing the demand.

The sequence of system events is as follows. At the beginning of the first period, the firm replenishes new raw material inventory. Next, the demand is realized. If the raw material is enough, the firm manufactures products to meet the demand by its raw inventory; otherwise, the firm will urgently order the shortage by a higher cost. At the end of the period, customers return their used products. In the second period, based on new raw material inventory and the returned used products in the first period, the firm needs to make decision on the replenishment quantity of raw material inventory before realizing the demand. After realizing the demand, the firm needs to determine the production quantities of manufacturing and remanufacturing way. Here, we assume that the returned products in current period will be remanufactured in the next period. Therefore, the firm does not need to collect used products in the second period. We give the figure of event sequence in Figure 1.

The research aim of this paper is to determine the optimal replenishment quantity of new raw material inventory in each and the production quantities of manufacturing and remanufacturing way so as the expectation of firm's profit can be maximized.

Notation definitions:

$p_{s}=$ Selling price of marketable product 

$C=$ Replenishment cost for the raw material of manufac- turing per unit product

$c_{M}=$ Manufacturing cost of per unit product

$c_{E}=$ Urgent order cost of per unit shortage

$c_{R}=$ Remanufacturing cost of per unit returned product

$p_{R}=$ Acquisition price of per unit used product

$s_{M}=$ Salvage value of the material of manufacturing per unit product

$s_{R}=$ Salvage value of per unit returned product

$h=$ Inventory holding cost of per unit marketable product

$Q_{i}=$ Replenishment quantity of raw material inventory of period $i, i=1,2$

$q_{M}=$ Assigned quantity for manufacturing way after demand of period $i$ is realized

$q_{R}=$ Assigned quantity for remanufacturing way after demand of period $i$ is realized

$D_{i}=$ Demand of period $i, i=1,2$

$\theta\left(p_{R}\right)=$ Proportion of returning used products in the demand, and is an increasing function in $p_{R}$

$I_{i}=$ Initial inventory level of period $i$ for raw material inventory, $i=1,2$.

From the sequence of system events, we know the returned quantity of used products at the end of the first period can be denoted by $\theta\left(p_{R}\right) D_{1}$. For parameters $c_{M}, c_{R}, s_{M}, s_{R}$, we assume $c_{M} \geq c_{R}$ and $s_{M} \geq s_{R}$, which mean the production cost of remanufacturing way is less than manufacturing way and the salvage value of per unit used products is less than new raw material of producing per unit new product.

Given the acquisition price $p_{R}$, the replenishment quantity of raw material inventory $Q_{i}, i=1,2$, and the initial inventory level $I_{i}$, the expectation of the revenue in the first period is as follows:

$$
\begin{aligned}
\pi_{1}\left(I_{1}, Q_{1}\right)= & -C Q_{1}+p_{s} E\left[D_{1}\right]-c_{M} E\left[D_{1}\right] \\
& -h E\left(I_{1}+Q_{1}-D_{1}\right)^{+}-C_{E}\left(D_{1}-Q_{1}-I_{1}\right)^{+} \\
& -p_{R} E\left[\theta\left(p_{R}\right) D_{1}\right] .
\end{aligned}
$$

In (1), the first term is the replenishment cost for new raw material inventory, the second term is the selling income, the third term is the manufacturing cost, the fourth term is the inventory holding cost, the fifth is the urgent order cost, and the last term is the acquisition cost for used products. The expectation of the revenue in the second period is

$$
\pi_{2}\left(I_{2}, Q_{2}\right)=-C Q_{2}+E_{D_{2}}\left[\max \pi\left(q_{M}, q_{R}\right)\right]
$$

In (2), the first term is the replenishment cost for raw material inventory, and the second term is as follows:

$$
\begin{aligned}
& \max \pi\left(q_{M}, q_{R}\right)= p_{s}\left(q_{M}+q_{R}\right)-c_{M} q_{M}-c_{R} q_{R} \\
&+s_{M}\left(I_{2}+Q_{2}-q_{M}\right) \\
&+s_{R}\left(\theta\left(p_{R}\right) D_{1}-q_{R}\right) \\
& \text { s.t. }\left\{\begin{array}{l}
q_{M} \leq I_{2}+Q_{2} \\
q_{R} \leq \theta\left(p_{R}\right) D_{1} \\
q_{M}+q_{R} \leq D_{2} \\
q_{M}, q_{R} \geq 0 .
\end{array}\right.
\end{aligned}
$$

In (3), the first term is the selling income, and the second term is the manufacturing cost and the third term is the remanufacturing cost, and the fourth term is the salvage value for surplus raw material and the fifth term is the salvage value for surplus used products.

Let $\Pi\left(I_{1}, p_{R}\right)$ denote system optimal expected revenue for given the initial inventory level $I_{1}$ and the acquisition price $p_{R}$. Therefore, our aim is to find the optimal replenishment quantities $Q_{i}^{*}, i=1,2$ and the optimal production quantities $\left(q_{M}^{*}, q_{R}^{*}\right)$ so that

$$
\begin{gathered}
\Pi\left(I_{1}, p_{R}\right)=\max _{Q_{1}, Q_{2} \geq 0}\left\{\pi_{1}\left(I_{1}, Q_{1}\right)+E\left[\pi_{2}\left(I_{2}, Q_{2}\right)\right]\right\} \\
\text { subject to } I_{2}=\left(I_{1}+Q_{1}-D_{1}\right)^{+} .
\end{gathered}
$$

The above optimization model in (4) can be resolved by dynamic programming. In the following, we make the optimal analysis for the optimization model in (4).

\section{Optimal Analysis for Optimization Model}

By dynamic programming, we need first to solve the optimization problem in (3); for convenience, we name the problem as optimal assigning problem. Then we need to optimize the function in (2), and finally obtain the optimal system expectation revenue.

3.1. Optimal Decisions on Optimal Assigning Problem. When we make decisions on optimal manufacturing and remanufacturing quantities in the second period both demands and returns are realized, so we have the following proposition.

Proposition 1. Given the realized demand and return in the second period, the optimal production decisions $q_{M}^{*}$ and $q_{R}^{*}$ are as follows:

$$
\begin{gathered}
q_{M}^{*}=\min \left\{\left(D_{2}-\theta\left(p_{R}\right) D_{1}\right)^{+}, I_{2}+Q_{2}\right\}, \\
q_{R}^{*}=\min \left\{\theta\left(p_{R}\right) D_{1}, D_{2}\right\} .
\end{gathered}
$$

Proof. The optimal production decision problem in (3) is a linear programming problem. Because $c_{M} \geq c_{R}$ and $s_{M} \geq s_{R}$, that is, $c_{M}+s_{M} \geq c_{R}+s_{R}$, we have $p_{s}-c_{M}-s_{M} \leq p_{s}-$ $c_{R}-s_{R}$. It is obvious that the optimal solution should make 
the remanufacturing quantity increase as possible. So when $\theta\left(p_{R}\right) D_{1} \leq D_{2}$, we have

$$
\begin{gathered}
q_{R}^{*}=\theta\left(p_{R}\right) D_{1}, \\
q_{M}^{*}=\min \left\{D_{2}-\theta\left(p_{R}\right) D_{1}, I_{2}+Q_{2}\right\} .
\end{gathered}
$$

And when $\theta\left(p_{R}\right) D_{1}>D_{2}$, we have

$$
q_{R}^{*}=D_{2}, \quad q_{M}^{*}=0 .
$$

Therefore, $q_{M}^{*}=\min \left\{\left(D_{2}-\theta\left(p_{R}\right) D_{1}\right)^{+}, I_{2}+Q_{2}\right\}$ and $q_{R}^{*}=$ $\min \left\{\theta\left(p_{R}\right) D_{1}, D_{2}\right\}$.

Proposition 1 shows that the optimal production rule in the second period is to satisfy the demand by remanufacturing way as possible, only when the demand cannot be satisfied completely by remanufacturing way, the manufacturing way is considered.

3.2. Optimal Replenishment Decision in the Second Period. Let $y_{2}=I_{2}+Q_{2}$, it denotes the inventory level after replenishing the raw material inventory. And from Proposition 1, we can rewrite (2) as follows:

$$
\begin{aligned}
\pi_{2}\left(I_{2}, y_{2}\right)= & -C\left(y_{2}-I_{2}\right)+\left(p_{s}-c_{M}-s_{M}\right) \\
& \times E\left[\min \left\{\left(D_{2}-\theta\left(p_{R}\right) D_{1}\right)^{+}, y_{2}\right\}\right] \\
& +\left(p_{s}-c_{R}-s_{R}\right) E\left[\min \left\{\theta\left(p_{R}\right) D_{1}, D_{2}\right\}\right] \\
& +s_{M} y_{2}+s_{R} E\left[\theta\left(p_{R}\right) D_{1}\right] .
\end{aligned}
$$

Theorem 2. For $\pi_{2}\left(I_{2}, y_{2}\right)$ in (8), there are the following.

(a) $\pi_{2}\left(I_{2}, y_{2}\right)$ is jointly concave in $I_{2}$ and $y_{2}$.

(b) The equation $\partial \pi_{2}\left(I_{2}, y_{2}\right) / \partial y_{2}=0$ has unique solution.

Proof. It is obvious that $E\left[\min \left\{\left(D_{2}-\theta\left(p_{R}\right) D_{1}\right)^{+}, y_{2}\right\}\right]$ is concave in $y_{2}$, and other parts in (8) are linear in $I_{2}$ and $y_{2}$. Therefore, $\pi_{2}\left(I_{2}, y_{2}\right)$ is jointly concave in $I_{2}$ and $y_{2}$.

The first-order derivative of $\pi_{2}\left(I_{2}, y_{2}\right)$ about $y_{2}$ is

$$
\begin{aligned}
\frac{\partial \pi_{2}\left(I_{2}, y_{2}\right)}{\partial y_{2}}= & -C+s_{M}+\left(p_{s}-c_{M}-s_{M}\right) \\
& \times \operatorname{Pr}\left\{\left(D_{2}-\theta\left(p_{R}\right) D_{1}\right)^{+} \geq y_{2}\right\} .
\end{aligned}
$$

Because $p_{s}-c_{M}-s_{M}-\left(C-s_{M}\right)=p_{s}-c_{M}-C>0$ and $C-s_{M}>0$, there must exist a certain $y_{2}$ satisfying the following equation:

$$
\operatorname{Pr}\left\{\left(D_{2}-\theta\left(p_{R}\right) D_{1}\right)^{+} \geq y_{2}\right\}=\frac{C-s_{M}}{p_{s}-c_{M}-s_{M}} .
$$

Therefore, $\partial \pi_{2}\left(I_{2}, y_{2}\right) / \partial y_{2}=0$ must exist.

Theorem 2 shows that the optimal inventory level must exist and can be solved by $\partial \pi_{2}\left(I_{2}, y_{2}\right) / \partial y_{2}=0$. The optimal decision rule is given in the following proposition.
Proposition 3. Given inventory level $I_{2}$, the optimal replenishment decision in the second period is as follows:

$$
Q_{2}^{*}= \begin{cases}S_{2}-I_{2}-\theta\left(p_{R}\right) D_{1} & I_{2}+\theta\left(p_{R}\right) D_{1}<S_{2} \\ 0 & I_{2}+\theta\left(p_{R}\right) D_{1} \geq S_{2}\end{cases}
$$

where $S_{2}$ satisfies

$$
\operatorname{Pr}\left\{D_{2} \geq S_{2}\right\}=\frac{C-s_{M}}{p_{s}-c_{M}-s_{M}} .
$$

Proof. We know that

$$
\begin{aligned}
\operatorname{Pr} & \left\{\left(D_{2}-\theta\left(p_{R}\right) D_{1}\right)^{+} \geq y_{2}\right\} \\
& =\operatorname{Pr}\left\{D_{2} \geq \theta\left(p_{R}\right) D_{1}, D_{2}-\theta\left(p_{R}\right) D_{1} \geq y_{2}\right\} \\
& =\operatorname{Pr}\left\{D_{2} \geq \theta\left(p_{R}\right) D_{1}, D_{2}-\theta\left(p_{R}\right) D_{1} \geq y_{2}\right\} \\
& =\operatorname{Pr}\left\{D_{2} \geq y_{2}+\theta\left(p_{R}\right) D_{1}\right\} .
\end{aligned}
$$

Let $z_{2}=\theta\left(p_{R}\right) D_{1}+y_{2}$; it can denote the whole inventory after the new raw material inventory is replenished, where the whole inventory includes new raw material inventory and used product inventory. Therefore, $S_{2}$ of satisfying $\operatorname{Pr}\left\{D_{2} \geq\right.$ $\left.z_{2}\right\}=\left(C-s_{M}\right) /\left(p_{s}-c_{M}-s_{M}\right)$ also must satisfy $\operatorname{Pr}\left\{\left(D_{2}-\right.\right.$ $\left.\left.\theta\left(p_{R}\right) D_{1}\right)^{+} \geq y_{2}\right\}=\left(C-s_{M}\right) /\left(p_{s}-c_{M}-s_{M}\right)$, where $y_{2}=$ $S_{2}-\theta\left(p_{R}\right) D_{1}$.

In the following, we consider two cases.

Case 1. When $I_{2}+\theta\left(p_{R}\right) D_{1}<S_{2}$, from Part (a) in Theorem 2, for any $Q_{2}$ satisfying $I_{2}+Q_{2}+\theta\left(p_{R}\right) D_{1} \leq S_{2}$, we have

$$
\frac{\partial \pi_{2}\left(I_{2}, I_{2}+Q_{2}+\theta\left(p_{R}\right) D_{1}\right)}{\partial y_{2}} \geq \frac{\partial \pi_{2}\left(I_{2}, S_{2}\right)}{\partial y_{2}}=0 .
$$

And for any $Q_{2}$ satisfying $I_{2}+Q_{2}+\theta\left(p_{R}\right) D_{1}>S_{2}$,

$$
\frac{\partial \pi_{2}\left(I_{2}, I_{2}+Q_{2}+\theta\left(p_{R}\right) D_{1}\right)}{\partial y_{2}}<\frac{\partial \pi_{2}\left(I_{2}, S_{2}\right)}{\partial y_{2}}=0 .
$$

So $Q_{2}^{*}$ should satisfy $I_{2}+\theta\left(p_{R}\right) D_{1}+Q_{2}^{*}=S_{2}$, that is, $Q_{2}^{*}=$ $S_{2}-I_{2}-\theta\left(p_{R}\right) D_{1}$.

Case 2. When $I_{2}+\theta\left(p_{R}\right) D_{1} \geq S_{2}$, for any $Q_{2} \geq 0$, we have

$$
\begin{aligned}
\frac{\partial \pi_{2}\left(I_{2}, I_{2}+Q_{2}+\theta\left(p_{R}\right) D_{1}\right)}{\partial y_{2}} \\
\quad \leq \frac{\partial \pi_{2}\left(I_{2}, I_{2}+\theta\left(p_{R}\right) D_{1}\right)}{\partial y_{2}} \leq \frac{\partial \pi_{2}\left(I_{2}, S_{2}\right)}{\partial y_{2}}=0
\end{aligned}
$$

so $Q_{2}^{*}=0$.

In summary,

$$
Q_{2}^{*}= \begin{cases}S_{2}-I_{2}-\theta\left(p_{R}\right) D_{1} & I_{2}+\theta\left(p_{R}\right) D_{1}<S_{2}, \\ 0 & I_{2}+\theta\left(p_{R}\right) D_{1} \geq S_{2} .\end{cases}
$$

Proposition 3 holds.

Proposition 3 shows that the basic inventory policy is still optimal. We call $S_{2}$ as the optimal inventory level in the second period. It is obvious that it is unrelated to acquisition price. 
3.3. Optimal Replenishment Decision in the First Period. For the convenience of description, we define

$$
\begin{aligned}
\Pi_{2}\left(I_{2}\right)=\max _{y_{2} \geq I_{2}}\{ & -C y_{2}+\left(p_{s}-c_{M}-s_{M}\right) \\
& \times E\left[\min \left\{\left(D_{2}-\theta\left(p_{R}\right) D_{1}\right)^{+}, y_{2}\right\}\right] \\
& +\left(p_{s}-c_{R}-s_{R}\right) \times E\left[\min \left\{\theta\left(p_{R}\right) D_{1}, D_{2}\right\}\right] \\
& \left.+s_{M} y_{2}+s_{R} \theta\left(p_{R}\right) D_{1}\right\} .
\end{aligned}
$$

From (8), we know that

$$
\Pi_{2}\left(I_{2}\right)=\max _{y_{2} \geq I_{2}}\left\{\pi_{2}\left(I_{2}, y_{2}\right)-C I_{2}\right\}
$$

or $\Pi_{2}\left(I_{2}\right)+C I_{2}=\max _{y_{2} \geq I_{2}}\left\{\pi_{2}\left(I_{2}, y_{2}\right)\right\}$.

From dynamic programming, we have

$$
\begin{aligned}
& \Pi\left(I_{1}, p_{R}, Q_{1}\right)=\max _{Q_{1} \geq 0}\{ \pi_{1}\left(I_{1}, Q_{1}\right) \\
&+E\left[\Pi_{2}\left(\left(I_{1}+Q_{1}-D_{1}\right)^{+}\right)\right. \\
&\left.\left.+C\left(I_{1}+Q_{1}-D_{1}\right)^{+}\right]\right\} .
\end{aligned}
$$

For analyzing the property of $\Pi\left(I_{1}, p_{R}, Q_{1}\right)$, we give the following lemma.

Lemma 4. (a) If $f(x, y)$ is jointly concave in $x$ and $y$ and $C$ is a convex set on $R^{2}$, then $g(x)=\max _{y \in C} f(x, y)$ is also concave in $x$.

(b) If $h(x)$ is concave and nonincreasing and $f(x)$ is convex, then $g(x)=h(f(x))$ is also concave.

Proof. For the proof of (a) and (b), please see Pages 84 and 81 in Boyd and Vandenberghe [14]. is,

Let $H\left(I_{1}, Q_{1}\right)$ denote the objective function of (20), that

$$
\begin{aligned}
& H\left(I_{1}, Q_{1}\right) \\
&=\pi_{1}\left(I_{1}, Q_{1}\right)+E {\left[\Pi_{2}\left(\left(I_{1}+Q_{1}-D_{1}\right)^{+}\right)\right.} \\
&\left.+C\left(I_{1}+Q_{1}-D_{1}\right)^{+}\right] .
\end{aligned}
$$

Let $y_{1}=I_{1}+Q_{1}$, it denotes the inventory level after the raw material inventory is replenished. And from (1), we have

$$
\begin{aligned}
H\left(I_{1}, y_{1}\right)= & -C\left(y_{1}-I_{1}\right) \\
+ & E\left[\left(p_{s}-c_{M}-p_{R} \theta\left(p_{R}\right)\right) D_{1}\right. \\
& \left.\quad-h\left(y_{1}-D_{1}\right)^{+}-C_{E}\left(D_{1}-y_{1}\right)^{+}\right] \\
& +E\left[\Pi_{2}\left(\left(y_{1}-D_{1}\right)^{+}\right)+C\left(y_{1}-D_{1}\right)^{+}\right] .
\end{aligned}
$$

Theorem 5. $H\left(I_{1}, y_{1}\right)$ in (22) is concave in $y_{1}$.
Proof. We divide $H\left(I_{1}, y_{1}\right)$ into two parts $W_{1}\left(I_{1}, y_{1}\right)$ and $W_{2}\left(I_{1}, y_{1}\right)$, where

$$
\begin{aligned}
W_{1}\left(I_{1}, y_{1}\right)= & \left(p_{s}-c_{M}-p_{R} \theta\left(p_{R}\right)\right) E\left[D_{1}\right] \\
& -h E\left[\left(y_{1}-D_{1}\right)^{+}\right]-C_{E} E\left[\left(D_{1}-y_{1}\right)^{+}\right] \\
& +C E\left[\left(y_{1}-D_{1}\right)^{+}\right], \\
W_{2}\left(I_{1}, y_{1}\right)= & E\left[\Pi_{2}\left(\left(y_{1}-D_{1}\right)^{+}\right)\right]+C\left(y_{1}-I_{1}\right) .
\end{aligned}
$$

The first-order derivative of $W_{1}\left(I_{1}, y_{1}\right)$ about $y_{1}$ is

$$
\frac{\partial W_{1}\left(I_{1}, y_{1}\right)}{\partial y_{1}}=(C-h) \operatorname{Pr}\left\{y_{1} \geq D_{1}\right\}+C_{E} \operatorname{Pr}\left\{y_{1}<D_{1}\right\},
$$

and the second-order derivative of $W_{1}\left(I_{1}, y_{1}\right)$ about $y_{1}$ is

$$
\frac{\partial^{2} W_{1}\left(I_{1}, y_{1}\right)}{\partial y_{1}^{2}}=\left(C-h-C_{E}\right) f_{D_{1}}\left(y_{1}\right)<0,
$$

so $W_{1}\left(I_{1}, y_{1}\right)$ is concave in $y_{1}$.

In the following, we will prove that $W_{2}\left(I_{1}, y_{1}\right)$ is still concave in $y_{1}$. From Part (a) in Theorem 2, we know that $\pi_{2}\left(I_{2}, y_{2}\right)$ is jointly concave in $I_{2}$ and $y_{2}$, so $\max _{y_{2} \geq I_{2}}\left\{\pi_{2}\left(I_{2}, y_{2}\right)\right\}$ is also concave in $I_{2}$ by Part (a) in Lemma 4. And From (19), we have

$$
\Pi_{2}\left(I_{2}\right)=\max _{y_{2} \geq I_{2}}\left\{\pi_{2}\left(I_{2}, y_{2}\right)\right\}-C I_{2},
$$

so $\Pi_{2}\left(I_{2}\right)$ is also concave in $I_{2}$. Moreover, it is nonincreasing in $I_{2}$.

Let $\varphi(y)=(y)^{+}$; it is convex in $y$. From Part (b) in Lemma 4, we know that $\Pi_{2}\left(\varphi\left(y_{1}\right)\right)$ is concave in $y_{1}$. Therefore, $E\left[\Pi_{2}\left(\varphi\left(y_{1}-D_{1}\right)\right)\right]=E\left[\Pi_{2}\left(\left(y_{1}-D_{1}\right)^{+}\right)\right]$is also concave in $y_{1}$, and $W_{2}\left(I_{1}, y_{1}\right)$ is concave in $y_{1}$.

Therefore, $H\left(I_{1}, y_{1}\right)$ in (22) is concave in $y_{1}$ as follows:

$$
\begin{aligned}
\frac{\partial H\left(I_{1}, y_{1}\right)}{\partial y_{1}}= & -C+(C-h) \operatorname{Pr}\left\{y_{1} \geq D_{1}\right\} \\
& +C_{E} \operatorname{Pr}\left\{y_{1}<D_{1}\right\}+\frac{\partial E\left[\Pi_{2}\left(\left(y_{1}-D_{1}\right)^{+}\right)\right]}{\partial y_{1}} .
\end{aligned}
$$

Let $S=\min \left\{y_{1} \mid \partial H\left(0, y_{1}\right) / \partial y_{1} \leq 0, y_{1} \geq 0\right\}$, so we have the following theorem.

Theorem 6. S must exist.

Proof. From $E\left[\Pi_{2}\left(\left(y_{1}-D_{1}\right)^{+}\right)\right]=\int_{-\infty}^{y_{1}} \Pi_{2}(0) d F(x)+$ $\int_{y_{1}}^{+\infty} \Pi_{2}\left(y_{1}-x\right) d F(x)$, we have

$$
\frac{d E\left[\Pi_{2}\left(\left(y_{1}-D_{1}\right)^{+}\right)\right]}{d y_{1}}=\int_{y_{1}}^{+\infty} \frac{d \Pi_{2}\left(y_{1}-x\right)}{d y_{1}} d F(x) .
$$


TABLE 1: Basic parameter setting.

\begin{tabular}{lcccccccccccc}
\hline Parameter & $p_{s}$ & $C$ & $C_{E}$ & $h$ & $c_{M}$ & $c_{r}$ & $s_{M}$ & $s_{R}$ & $a_{i}$ & $\sigma$ & $k$ & $p_{R}$ \\
\hline Range & 3.5 & 1.8 & 2.2 & 0.2 & 0.6 & 0.5 & 0.8 & 0.6 & 1000 & $40 \sim 300$ & $0.1 \sim 0.8$ & $0.5 \sim 1.3$ \\
\hline
\end{tabular}

And because $\Pi_{2}\left(I_{2}\right)$ is nonincreasing in $I_{2}$, we have $d E\left[\Pi_{2}\left(\left(y_{1}-D_{1}\right)^{+}\right)\right] / d y_{1} \leq 0$, and

$$
\lim _{y_{1} \rightarrow \infty} \frac{\partial H\left(I_{1}, y_{1}\right)}{\partial y_{1}}=-h+\lim _{y_{1} \rightarrow \infty} \frac{\partial E\left[\Pi_{2}\left(\left(y_{1}-D_{1}\right)^{+}\right)\right]}{\partial y_{1}} \leq-h
$$

so $S$ must exist.

Similar to Proposition 3, we have Proposition 7.

Proposition 7. Given the initial inventory level $I_{1}$, the optimal replenishment decision in the first period is given as follows:

$$
Q_{1}^{*}= \begin{cases}S_{1}-I_{1} & I_{1}<S_{1} \\ 0 & I_{1} \geq S_{1}\end{cases}
$$

where $S_{1}$ satisfies

$$
S_{1}=\min \left\{y_{1} \mid \frac{\partial H\left(0, y_{1}\right)}{\partial y_{1}} \leq 0, y_{1} \geq 0\right\}
$$

Proof. The proof is similar to Proposition 3.

\section{Numerical Study}

In this section, we study management insights by numerical examples and make the sensitivity analysis of optimal expected profit with respect to other parameters.
We assume the demand in each period to be $D_{i}=$ $a_{i}+\varepsilon_{i}$. Random parts $\varepsilon_{1}$ and $\varepsilon_{2}$ are independent and identical distribution and are assumed to follow the normal distribution with the zero mean and the deviation $\sigma$. The proportion of returning used products in all demand for the first period is assumed to be $\theta\left(p_{R}\right)=1-e^{-k p_{R}}$. The parameter setting is provided in Table 1.

We analyze the following cases. (i) The effects of acquisition price and standard deviation of demand on system optimal expected profit. (ii) The effects of the return sensitive coefficient in acquisition price on system optimal expected profit. (iii) The effects of sensitive coefficient and standard deviation of demand on percent improvement in optimal expected profit.

Figure 2 shows that the system optimal expected profit is a concave function in acquisition price, which means that we can determine an optimal acquisition price for any set of parameter setting. It is obvious that a comfortable acquisition price can supply production material by a lower cost, but the profit of unit used product is decreasing as the acquisition price is increasing and it is possible that remanufacturing has no profit when the acquisition price is too large. Moreover, Figure 1 also shows that the system optimal expected profit is decreasing as the standard deviation of demand is increasing.

Figure 3 shows that the system optimal expected profit is increasing as different sensitive coefficients $k$ are increasing. Because the return proportion is more sensitive on acquisition price, the firm can acquire used product more easily, the acquisition cost is lower, and the remanufacturing profit is larger.

To analyze the change of expected profit, we define a percent improvement in the expected profit by the following:

$$
\begin{aligned}
& \text { Percent improvement in expectation profit } \\
& =\frac{\text { Optimal expected profit }\left(p_{R} \text { is nonzero }\right)-\text { Optimal expected profit }\left(p_{R} \text { is zero }\right)}{\text { Optimal expected profit }\left(p_{R} \text { is zero }\right)} \times 100 \% \text {. }
\end{aligned}
$$

From Figure 4, we can know that the standard deviation is larger, the percent improvement in expectation profit is larger, the return process is more sensitive, and the percent improvement in expectation profit is larger. Return process can be viewed as another supply source, which may decrease the supply risk, and when the standard deviation of demand is larger, the action of multichannel for decreasing risk is larger. The return proportion is more sensitive on acquisition price, and the firm can control risk by a lower cost, so the profit improvement is larger.

\section{Conclusion}

In this paper, we study an inventory control and production planning problem when a firm with manufacturing and remanufacturing production way faces stochastic demand. In order to stimulate the return of used products, the firm offers a return compensation for the customers who return used products. Under the return stimulating policy, the return process depends on the demand process. Based on the setting, we investigate optimal policies on inventory replenishment 


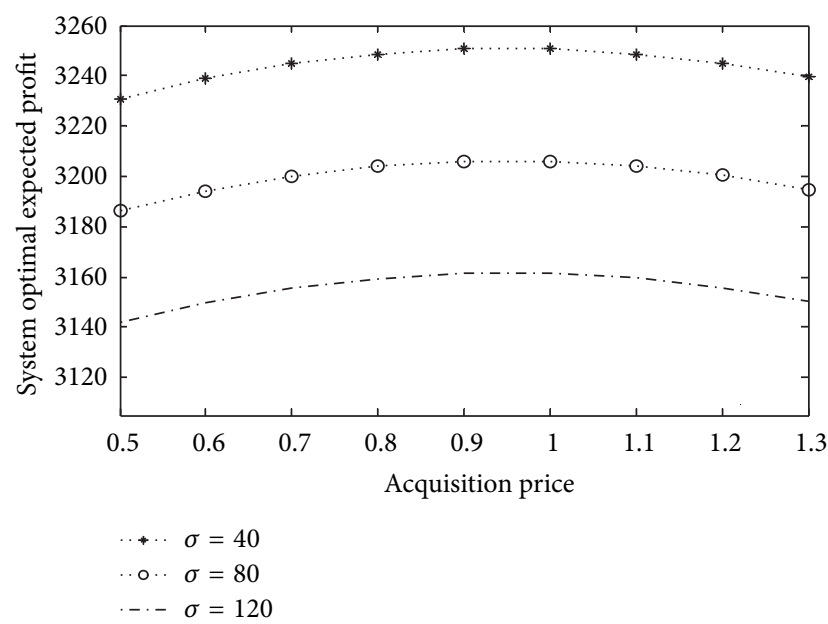

FIGURE 2: Optimal expected profits for different standard deviations.

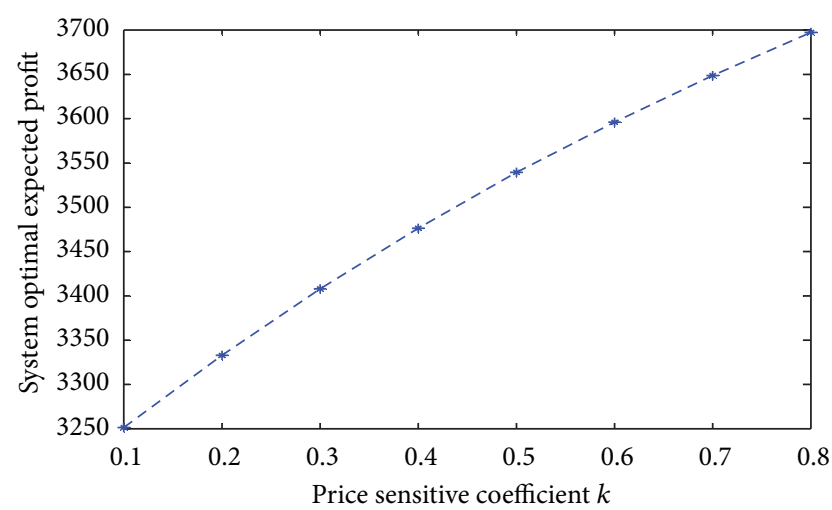

FIGURE 3: Optimal expected profits for different sensitive coefficients $k$.

and production planning problem for a single item twoperiod inventory system. Firstly, the problem is formulated into a three-stage stochastic programming problem. Secondly, the optimal production policies on manufacturing and remanufacturing for the realized demand are given. Next, we prove the objective function for each stage to be concave in decision variable and prove the existence and the uniqueness of optimal solutions. Moreover, the basic inventory policy is proved to be optimal for each period, and the optimal inventory levels are unrelated to acquisition price. Finally, we investigate numerical studies to analyze managerial insights.

There are some possible extensions in the future investigation. The current problem only considers inventory decisions and a single type of used product quality class. One extension would be to consider to make joint decisions on inventory replenishment and acquisition price. Another extension is to study the multitype product quality class setting.

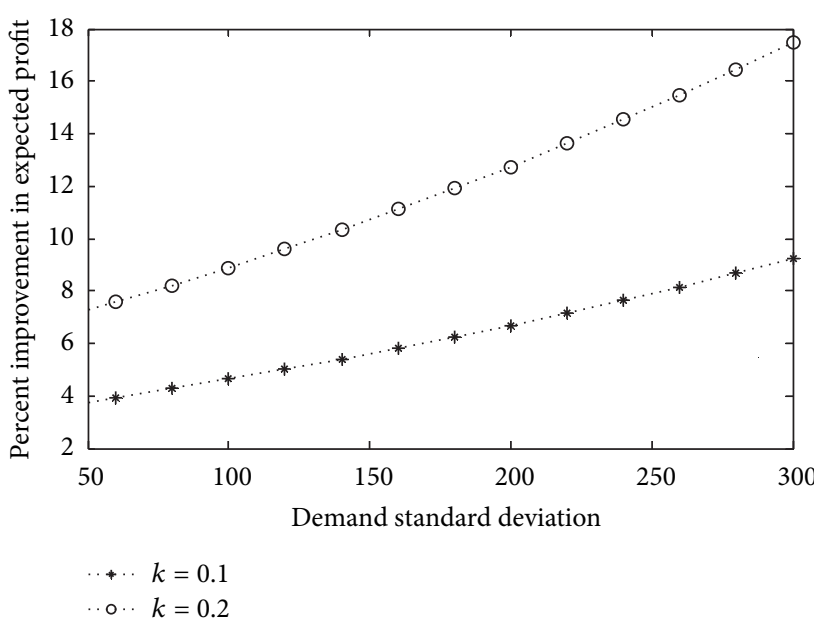

FIGURE 4: Percent improvement in the expected profit.

\section{Acknowledgment}

This research is supported by National Natural Science Foundation of China (NSFC), Research Fund nos. 71002106 and 71001106.

\section{References}

[1] M. Fleischmann, Quantitative models for reverse logistics [Ph.D. thesis], Erasmus University, Rotterdam, The Netherlands, 2000.

[2] M. Fleischmann and R. Kuik, "On optimal inventory control with independent stochastic item returns," European Journal of Operational Research, vol. 151, no. 1, pp. 25-37, 2003.

[3] Kiesmüller, "A new approach for controlling a hybrid stochastic manufacturing/remanufacturing system with inventories and different leadtimes," European Journal of Operational Research, vol. 147, no. 1, pp. 62-71, 2003.

[4] K. Inderfurth, "Optimal policies in hybrid manufacturing/remanufacturing systems with product substitution," International Journal of Production Economics, vol. 90, no. 3, pp. 325-343, 2004.

[5] G. A. DeCroix and P. H. Zipkin, "Inventory management for an assembly system with product or component returns," Management Science, vol. 51, no. 8, pp. 1250-1265, 2005.

[6] G. A. DeCroix, "Optimal policy for a multiechelon inventory system with remanufacturing," Operations Research, vol. 54, no. 3, pp. 532-543, 2006.

[7] S. X. Zhou, Z. T. Tao, and X. C. Chao, "Optimal control of inventory systems with multiple types of remanufacturable products," Manufacturing and Service Operations Management, vol. 13, no. 1, pp. 20-34, 2011.

[8] S. X. Zhou and Y. Yu, "Optimal product acquisition, pricing, and inventory management for systems with remanufacturing," Operations Research, vol. 59, no. 2, pp. 514-521, 2011.

[9] M. Fleischmann, J. M. Bloemhof-Ruwaard, R. Dekker, E. van der Laan, J. A. E. E. van Nunen, and L. N. van Wassenhove, "Quantitative models for reverse logistics: a review," European Journal of Operational Research, vol. 103, no. 1, pp. 1-17, 1997.

[10] R. Dekker, M. Fleischmann, K. Inderfurth, and L. N. V. Wassenhove, Reverse Logistics Quantitative Models for ClosedLoop Supply Chains, Springer, 1st edition, 2004. 
[11] G. P. Kiesmüller and E. A. van der Laan, "An inventory model with dependent product demands and returns," International Journal of Production Economics, vol. 72, no. 1, pp. 73-87, 2001.

[12] I. Dobos and K. Richter, "An extended production/recycling model with stationary demand and return rates," International Journal of Production Economics, vol. 90, no. 3, pp. 311-323, 2004.

[13] B. Atamer, I. S. Bakal, and Z. P. Bayındır, "Optimal pricing and production decisions in utilizing reusable containers," International Journal of Production Economics, 2011.

[14] S. Boyd and L. Vandenberghe, Convex Optimization, Cambridge University Press, Cambridge, Mass, USA, 2004. 


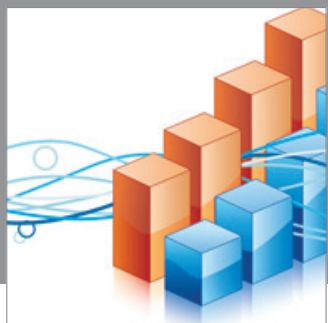

Advances in

Operations Research

mansans

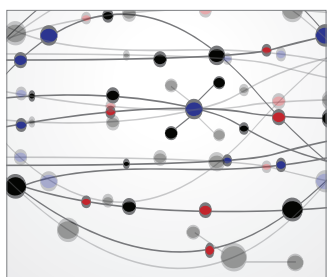

The Scientific World Journal
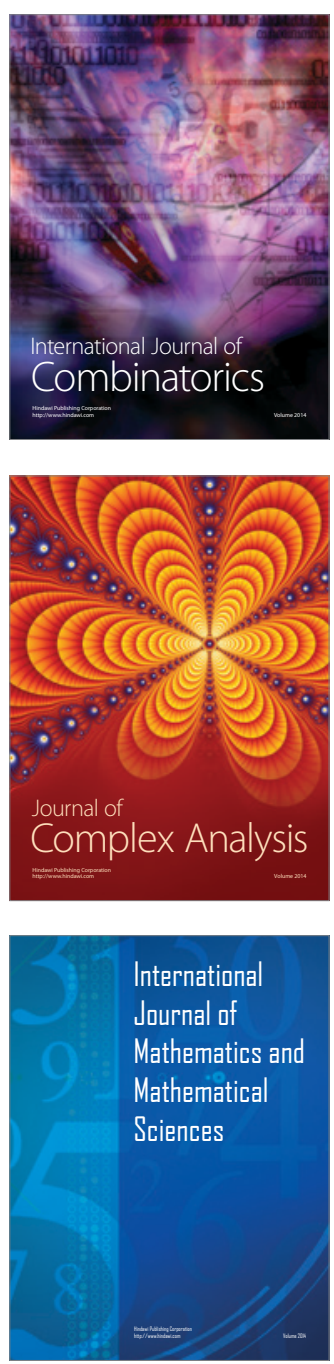
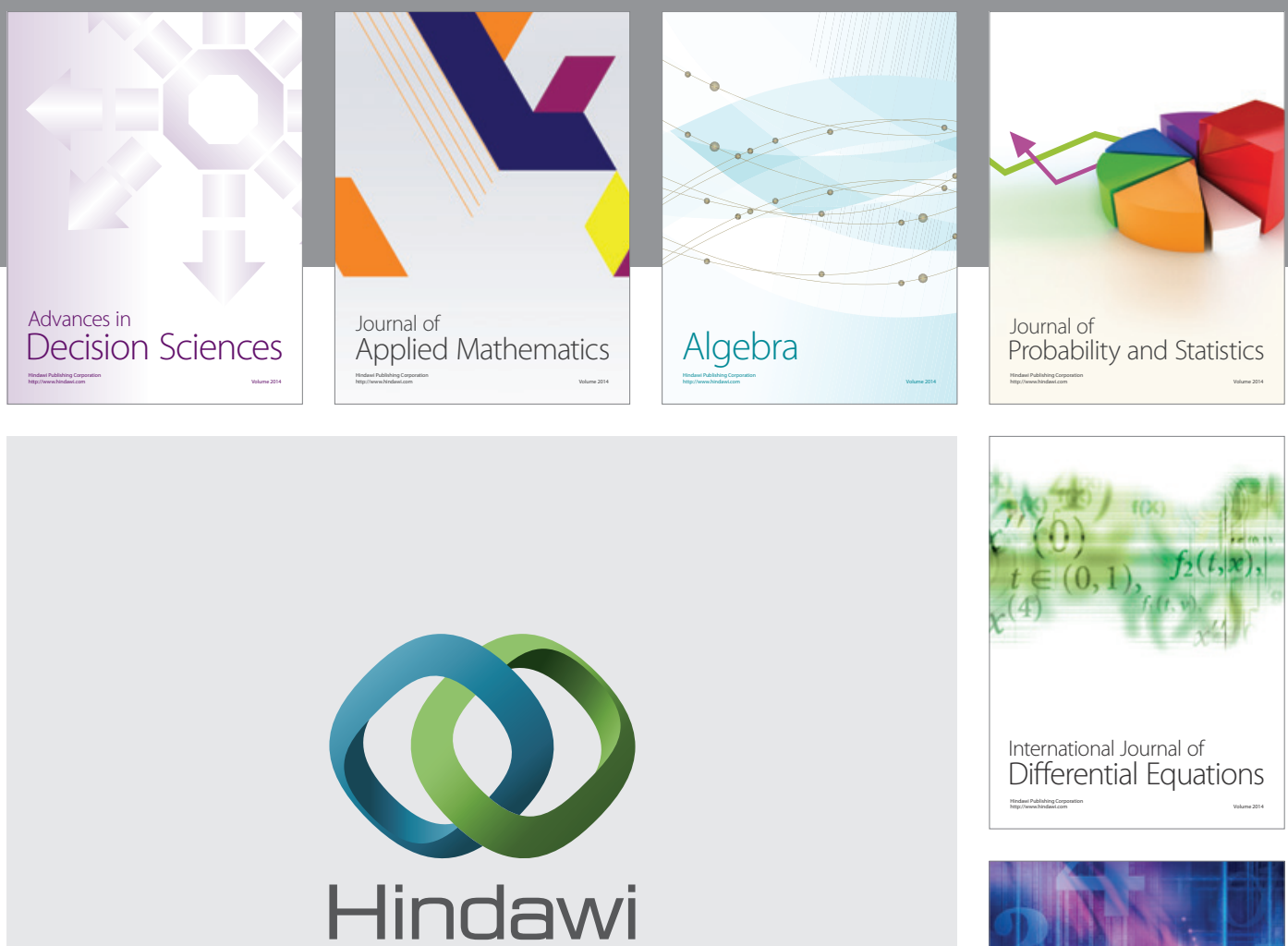

Submit your manuscripts at http://www.hindawi.com
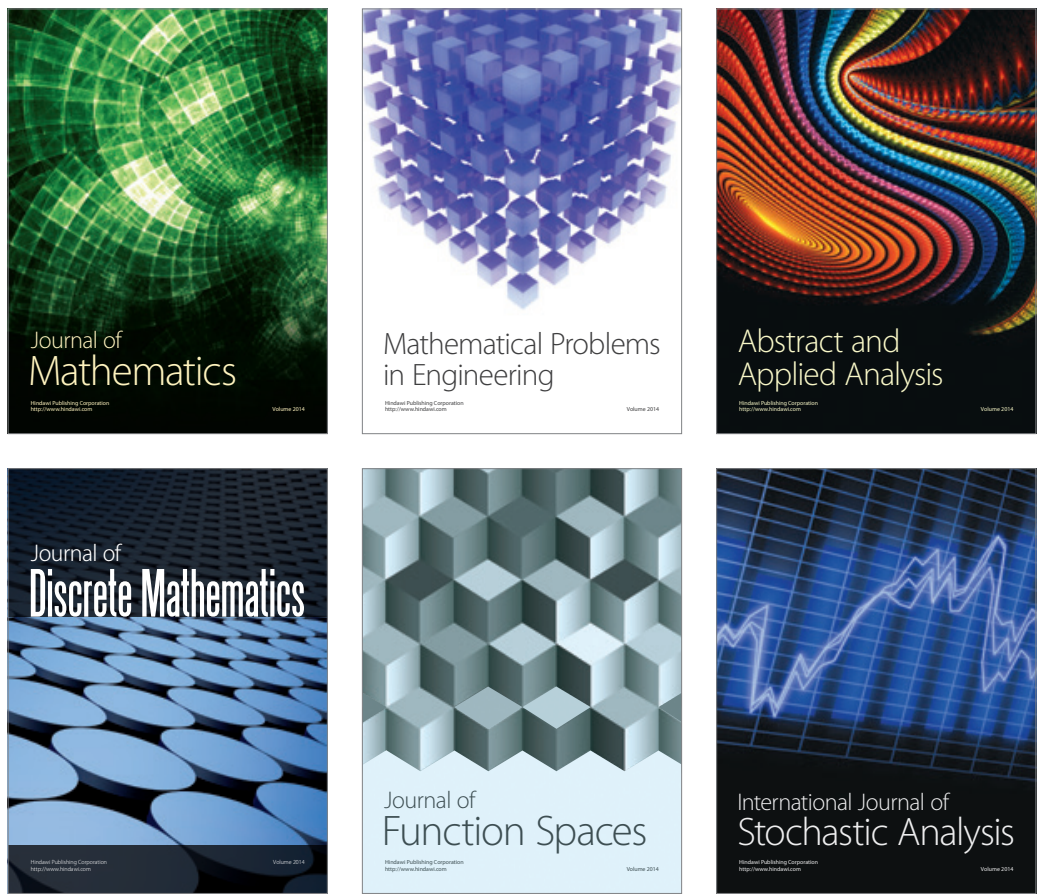

Journal of

Function Spaces

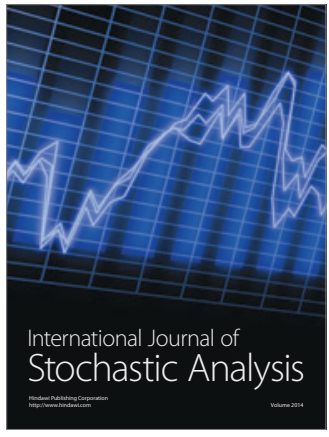

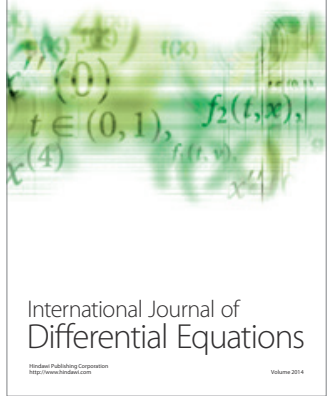
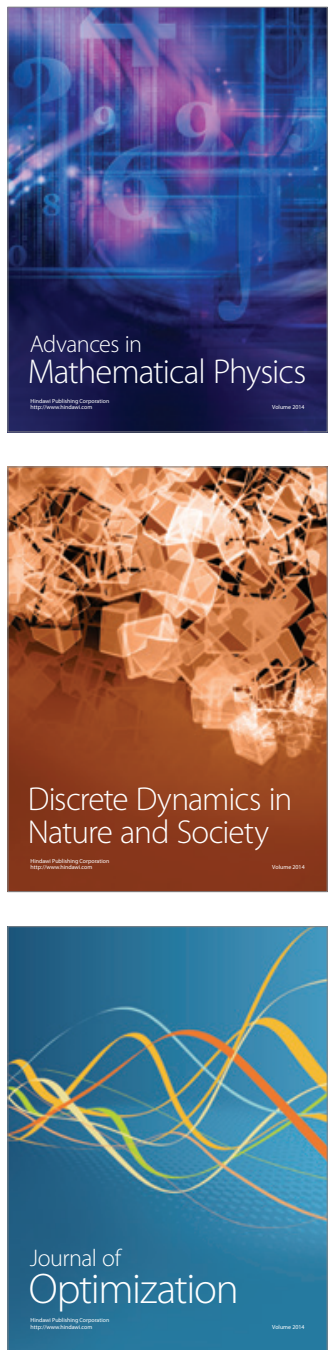